\title{
Research on the Education of Online Consumption Concept for College Students in the New Era of China
}

\author{
Xiaoyan Wang \\ China Jiliang University \\ Academy of Marxism \\ Zhejiang, Hangzhou, China \\ E-mail1337068805@qq.com
}

\begin{abstract}
In the new era, consumption will further play its fundamental role in promoting national economic development and creating a better life. At present, network consumption has become a major consumption pattern. College students, as a part of China's national consumer groups, whose consumption habits and consumption concepts have a significant impact on the consumption habits and concepts of the whole society. Currently, college students' online consumption concept in the new era harbors both positive and negative effects. This paper analyzes the current situation of college students' consumption and also the causes and countermeasures of college students' consumption with the adoptation of questionnaires, literature search, news research and other methods from the perspectives of social environment, school environment, family environment and legal environment. It is hoped that the findings of this paper can contribute to the building of a sound consumption environment in colleges and universities.
\end{abstract}

Keywords-China's new era; College students; Online consumption; Consumption concept

\section{INTRODUCTION}

In the report entitled Secure a Decisive Victory in Building a Moderately Prosperous Society in All Respects and Strive for the Great Success of Socialism with Chinese Characteristics for a New Era (hereinafter referred to as the nineteen report) which was made by General secretary $\mathrm{Xi}$ Jinping on behalf of the eighteenth Central Committee to The nineteenth National Congress of the Communist Party of China on the morning of October 18, 2017, General secretary $\mathrm{Xi}$ Jinping has repeatedly referred to "consumption", placing emphasis on strengthening the basic role of "consumption" in promoting national economic development and creating a better life.[1].But with the rapid advancement of the Internet, Internet of Things, big data, cloud computing, artificial intelligence and other technologies, it will have a huge impact on the changes in consumer habits and consumer attitudes, if not take correct, reasonable and scientific measures to point, It will inevitably have negative effects or even negative effects. This is especially true for this particular group of college students. College students have no or very little income, but they are positive consumers and the main practitioners of the popular consumer culture of online consumption. Having a healthy and rational online consumption concept is very important for their overall development.

\section{THE DEVELOPMENT TREND OF COLLEGE STUDENTS' NETWORK CONSUMPTION CONCEPT IN THE NEW ERA OF CHINA}

A. The Positive Development Trend of College Students' Network Consumption Concept in the New Era of China

1) Personalized Network Consumption Concept

Today's society is an era of advocating individuality, and people have changed from preaching their virtues to preaching their own personalities. As a young and energetic group, college students are naturally eager to publicize their individuality, constantly break through the rules and create their own style. The construction of the online consumption platform provides a stage for the personality display of college students. Through this approach, college students' satisfaction with things and their self-confidence are satisfied. The self-positioning of college students is not clear enough. Full self-affirmation and recognition by others are necessary conditions for college students to establish self-confidence. The variety of network products can meet the diverse needs of college students to a greater extent. In the process of online consumption, college students can fully express their own personality, and they can feel the value of self and get recognition and recognition.

\section{2) Rationalized Network Consumption Concept}

The popularity of online consumption has brought great convenience to people's lives, but it has also stimulated people's consumption needs, which also poses certain challenges to the consumption concept of college students. Under the temptation of material and colorful online consumption, some college students are still able to keep a clear head. A survey of the monthly living expenses of first-to-senior students at China Jiliang University shows: Online consumption is dominated by senior students, 
especially juniors and seniors. According to a survey of students who have experienced online consumption, $88.8 \%$ of students choose online consumption because the price is cheap. $83.6 \%$ of the students choose online consumption because it is convenient and fast. $74.6 \%$ of students choose online consumption because they choose Diverse. It can be seen that most of the students still use the consumption power to conduct online consumption. They hope to obtain high-quality and low-priced products through online consumption, which reflects the more rational side of their online consumption concept.

\section{3) Efficient Network Consumption Concept}

Marx once pointed out: "When people can't make their food and drink fully supplied in terms of quality and quantity, people can't be liberated." Once a certain range of needs is met, they will be freed and created. Needs" [2] Nowadays, the material life of contemporary people has been quite rich and rich, and the rich and comprehensive development of individuals has become the focus of attention of the modern society. Today's society is a learning society. On the Internet, college students not only pay attention to the consumption of material products such as clothing, food, electronic equipment, but also pay attention to the consumption of spiritual products such as books, learning materials and online courses about their future development. According to the survey, the proportion of students who have used online learning for books, learning materials and other academic developments has accounted for $19.6 \%$ of online consumption experience.

\section{B. The Negative Development Trend of College Students' Network Consumption Concept in the New Era of China}

\section{1) Addicted Network Consumption Concept}

With the development of e-commerce and logistics industry, various e-commerce platforms are emerging one after another, and the quality of various products is even more uneven. It takes more time and energy for college students to use the online platform to purchase goods. With the advent of the era of big data, marketing methods such as "private ordering" and "guessing you like" make network consumption not only specifically refer to a kind of consumption activity, but also accompanied by the indirect transmission of various information. For example, if you want to buy a skirt online, then the webpage will not only push a variety of skirts for you to choose, but also recommend shirts and jackets that match the skirts. Big data will calculate some of your desires and then push some Stylish web articles and some star wears, which invisibly give you more advice. This way of quickly obtaining a variety of information is undoubtedly very tempting for college students who are not yet mature, and it is easy for students to become psychologically dependent.

\section{2) Comparison of Network Consumption Concept}

When people use online consumption, they are not simply consumer goods. More people regard online consumption as a symbol of self-symbol. "When people consume and display their social identity, the identity value or social value of the goods is realized." [3]Through the goods consumed by the Internet and the way of shopping, people convey the symbolic representation of the self, in order to prove their identity and return themselves to a certain group of people. The diversity of online products is to help college students to better express their own personality. Through some social platforms, college students can publish their own information on products purchased and used, and watch the information published by others, which can effectively identify their peers and make it easier for friends to gain recognition. Feeling and favoring, make your vanity satisfied. Since college students have not really stepped into the society, they do not know that only self-improvement can truly realize the value of life before they can be respected by society. Instead, they superficially regard material transcendence as the satisfaction of need.

\section{3) Wasted Network Consumption Concept}

The types of online consumption are also endless, not only encompassing the consumer varieties in real life, but also spawning many novel consumer products, from some simple physical goods to more service products, such as online booking, online ordering. Meal services, etc., are changing our daily lifestyle habits. In the world of online consumption, college students tend to lose their way and lose their self, and become slaves of "things". The desire to consume college students stimulated by online consumption is not all necessary. It is infiltrated with the worship of famous brands, the pursuit of trends and the recognition of other consumer symbols. College students are particularly fond of new things, and their ability to accept them makes them more interested in new online products. Many college students may be able to save money for a new online game or online popular electronic products, just to satisfy your own curiosity and freshness.

\section{4) Extreme Network Consumption Concept}

In the past two years, through some news reports and online promotion articles, many bad consumer behaviors such as "naked loans" and "gambling" have spread among college students. Many students make reckless things for their own desires at the age of hard work, leaving themselves in a dilemma, and even extreme students choose to commit suicide. These children are regrettable, and this kind of behavior is arousing the high attention of the society. 


\section{THE ANALYSIS OF THE REASONS FOR THE POLARIZATION OF THE DEVELOPMENT TREND OF COLLEGE STUDENTS' NETWORK CONSUMPTION IN THE NEW ERA}

\section{A. Reasons from the Social Environment}

With the advent of the "big data" era, the technical means of information mining is also constantly enhanced. The personal information that can be searched by online media is also increasing. The proliferation of personal information also facilitates illegal businesses. Unscrupulous merchants will send various loan text messages and calls to students. Due to some factors that are not in place in network supervision, some unscrupulous merchants have Exaggerated the attributes of goods, and found some irresponsible stars and net red recommended products, which made some college students blindly listen to the network marketing and purchase some useless products. Various online lending platforms also target major customers to college students, taking advantage of the low income and easy to be induced by college students, advocating the advantage of early consumption, relaxing the threshold of online lending, and enticing college students to make loans to charge high interest rates.

\section{B. Reasons from the School Environment}

By consulting relevant materials and visiting college students, it was learned that $86 \%$ of the students did not receive information about the education of online consumption through the campus. For college students who are separated from parental supervision, college education is indispensable. Although some colleges and universities have also carried out some educational activities on the reasonable consumption of college students, the participation and recognition of students are not high, and the form of education is too single, which is difficult to attract students' interest. The lack of education in the network consumption concept of colleges and universities leads to the difficulty of forming a campus culture atmosphere with good network consumption concepts.

\section{Reasons from the Family Environment}

After entering the university campus, many students will go to school far away from home, and the education of their parents will be reduced. More parents worry that their children can't eat well at school, and they don't wear well. Therefore, they can give their children more living expenses within their own financial ability and meet their children's economic needs. Some parents are afraid that their children will be looked at in school when they are not rich. They should also satisfy their children's pursuit of brand-name consumer psychology. Too much love for children will also have an adverse impact on college students' consumption concept.

\section{Reasons from the Legal Environment}

At present, various online shopping platforms, network instalment lending platforms have sprung up, and the huge number makes China's supervision of some network platforms still not in place. Some platforms use the loopholes of network supervision to accumulate wealth, completely disregarding moral laws, using the characteristics of weak discrimination, low self-discipline, and vanity, and irresponsible for college students to sell their products and services, resulting in more The occurrence of many tragedies.

\section{Suggestion for China's New ERA College STUDENTS NETWORK CONSUMPTION CONCEPT SCIENTIFIC EDUCATION}

\section{A. Strengthening the Education and the Guiding Role of the Society in Setting up the Correct Network Consumption Concept for College Students}

The platform for college students to obtain more consultations comes from the network, strengthens the social responsibility education of online media, and uses its correct public opinion guidance to enable them to correctly guide college students to network consumption. An efficient network platform provides the public with a quick way to get information, but this approach is also two-sided. As the main force of network application, college students have not strong sense of self-selectivity in obtaining network information. Healthy and positive consumption concept has positive effect on college students undefined network consumption, otherwise it will bring negative effect. For the information release of the network platform, the official should set up a special supervision department to filter some false and advocating consumption information, and promote more active and green public service advertisements to facilitate college students to use the network to counter the bad network consumption behavior. Help college students consciously immune network consumption addiction.

\section{B. Strengthening the Educational Indoctrination Effect of Colleges and Universities on Establishing Correct Network Consumption Concept for College Students}

For colleges and universities, first of all, students should be educated on online consumption, including some lectures and volunteer activities. For example, to strengthen the traditional Chinese virtue education activities, educate students in school to develop habits of diligence and thrift, and to eliminate the consumption concept of luxury enjoyment. At the same time, it is also necessary to strengthen college students' online shopping risk prediction education. For example, you can push the online shopping risk assessment articles of college students through the campus public number and other platforms. The content can include the selection of shopping websites. You should choose some online shopping platforms with high reputation. When you select products, you should look at the evaluation of user products and make more reference. 
At the same time, we must educate students to be temperate in consumption, and do not advance consumption of goods that they cannot afford. Conduct some "campus loan" behaviors among college students and find out how to communicate with parents in time. Focus on promoting the hazards of campus loans and create a good consumer attitude. Secondly, it is necessary to strengthen the education of college students' correct outlook on life. The attitude of life and enjoyment will only make college students become more passive and slack. The correct guidance of life is especially important.

\section{Strengthening the Role of the Family in Setting an Educated Role Model for College Students to Establish a Correct Network Consumption Concept}

The lack of family "grateful education" makes some college students realize the hardships of parents to make money. They think that parents give themselves money to spend their money, lack gratitude, and it is difficult to control in the process of online consumption. As a parent of the students, students can learn how to work hard and let the students know the hard work of their parents. They should be grateful to the students. At the same time, both parents should lead by example. If the parents themselves are extravagant and wasteful, the children are easily affected by their parents. Produce bad consumer behavior. Parents need to communicate with the school in time to understand the dynamics of the students, do not over-love the children, and stop the unnecessary living needs of some students in school. In the supply of living expenses, we should also refer to the consumption level of college students, and provide students with living expenses in a controlled manner.

\section{Strengthening the Restriction on College Students Education to Establish a Correct Network Consumption Concept}

At the legal level, the legislature should strengthen the supervision of the network platform, implement the identity verification of the lenders on the online lending platform, and the student loans must be approved by the parents and the school. A unified standardization of implementation rules for the issuance of student loans by the online lending platform. Cancel the qualifications of some low-credit, low-credit lending platforms to borrow students. At the same time, the amount of borrowing for college students is limited, and the amount of interest for college students when it is difficult to repay is reduced.

\section{CONCLUSIONS}

The popularity of online consumption provides convenience for people's lives. The fast and efficient way is deeply favored by students. College students have become the mainstay of online consumption. With the use of high-tech data and intelligent technology in online consumption, it will also have a huge impact on the changes in consumption habits and consumption concepts of college students. If correct, reasonable and scientific educational measures are not taken, it will inevitably Negative effects or even negative effects. Therefore, from the four dimensions of society, colleges, families, and law, it can play an active role in strengthening the educational guiding role, educational indoctrination, educational role model, educational restraint, and educational support role of college students' online consumption concept. The macro-strategic goal of realizing consumption to promote national economic development and create a better life.

\section{REFERENCES}

[1] Ren Zhenyu. The new era of consumption is coming soon [N]. China Consumer News, 2018-01-05 (001).(In Chinese)

[2] Mas Selected Works (Volume I) [M]. Beijing: People's Publishing House. 1995: 76-79.(In Chinese)

[3] Yuka Gronau, Fun Sociology [M.] Nanjing: Nanjing University Press, 2002.(In Chinese)

[4] Rao Yu. Rational Discussion on the Values of Students' Consumption Education [J]. Teaching and Management, 2018(12): 75-77.(In Chinese)

[5] Leng Xiangyu. The Paradox of College Students' Values Education under the Influence of Consumerism [J]. School Party Construction and Ideological Education, 2017(03): 57-58.(In Chinese)

[6] Dai Weicai. Analysis on the Guidance of College Students' Correct Consumption Concept-—Taking the Phenomenon of "College Credit" Campus Market as an Example[J].Journal of Hebei Normal University(Education Science Edition),2017,19(05):105-111.(In Chinese)

[7] MU Zi. Research on the education of contemporary college students' online consumption concept [D]. China University of Geosciences (Beijing), 2015.(In Chinese) 